\title{
Leading, but not trailing, primes influence temporal order perception: Further evidence for an attentional account of perceptual latency priming
}

\author{
INGRID SCHARLAU \\ Bielefeld University, Bielefeld, Germany
}

\begin{abstract}
Presenting a masked prime leading a target influences the perceived onset of the masking target (perceptual latency priming; Scharlau \& Neumann, in press). This priming effect is explained by the asynchronous updating model (Neumann, 1982; Scharlau \& Neumann, in press): The prime initiates attentional allocation toward its location, which renders a trailing target at the same place consciously available earlier. In three experiments, this perceptual latency priming by leading primes was examined jointly with the effects of trailing primes in order to compare the explanation of the asynchronous updating model with the onset-averaging and the P-center hypotheses. Experiment 1 showed that an attended, as well as an unattended, prime leads to perceptual latency priming. In addition, a large effect of trailing primes on the onset of a target was found. As Experiment 2 demonstrated, this effect is quite robust, although smaller than that of a leading prime. In Experiment 3, masked primes were used. Under these conditions, no influence of trailing primes could be found, whereas perceptual latency priming persisted. Thus, a nonattentional explanation for the effect of trailing primes seems likely.
\end{abstract}

Presenting a masked prime at a location at which it is followed by a target reduces the perceptual latency of the target (perceptual latency priming; Scharlau \& Neumann, in press). This effect may be involved in cuing or priming effects as measured by reaction time (RT; see, e.g., Eriksen \& Collins, 1969; Eriksen \& Rohrbaugh, 1970; Posner, 1980; Posner, Snyder, \& Davidson, 1980). However, it has also been directly demonstrated by comparing the perceived onset of a cued or primed stimulus with that of an unprimed standard stimulus (temporal order judgment, TOJ; Aschersleben, 1999; Bachmann, 1989; Neumann, 1982; Neumann, Esselmann, \& Klotz, 1993; Scharlau \& Neumann, in press; Steglich \& Neumann, 2000). Perceptual latency priming has been found to have a size of approximately half the priming stimulus onset asynchrony (priming SOA: the interval between the onsets of a masked prime and a

A preliminary version of this manuscript, containing parts of the experimental data, was presented at the 2. Herbsttagung Experimentelle Kognitionspsychologie[2nd Autumn Conference on Experimental Cognitive Psychology], December 7-9, 2001, Rauischholzhausen, Germany. The research reported in this paper was supported by the Deutsche Forschungsgemeinschaft (DFG), Grant NE 366/5-2, to Odmar Neumann. I thank Ulrich Ansorge, Elena Carbone, Manfred Heumann, Matthias Kaper, Werner Klotz, and Odmar Neumann for valuable comments on earlier versions of the manuscript and Elaine Riehm for help with the English translation. Finally, I thank Jochen Müsseler and two anonymous reviewers for helpful comments on an earlier draft of this article. Correspondence should be sent to I. Scharlau, Department of Psychology, Bielefeld University, P.O. Box 1001 31, D-33501 Bielefeld, Germany (e-mail: ingrid.scharlau@ uni-bielefeld.de). masking target). For example, Neumann et al. (1993) reported effects of 16 and $26 \mathrm{msec}$ with an SOA of $34 \mathrm{msec}$ for masked and unmasked primes. In Steglich and Neumann (2000), there was a shift of $15 \mathrm{msec}$ with an SOA of 27 msec (Experiment 1). Recently, Scharlau and Neumann (in press) found effects of 33-40 $\mathrm{msec}$ with priming SOAs of $64 \mathrm{msec}$, and Aschersleben (1999) reported TOJ effects of approximately a quarter of the priming SOA of $81 \mathrm{msec}$.

These studies focused on dissociations between RT and judgment tasks. By contrast, Scharlau and Neumann (in press) studied the mechanism of perceptual latency priming in its own right. In this study, we demonstrated that the results fit well into an attentional model, the asynchronous updating model (AUM), which was originally developed to explain metacontrast masking (Neumann, 1978, 1979, 1982) and was later applied to such phenomena as the Fröhlich effect (Neumann \& Müsseler, 1990b; see also Neumann, 1990). ${ }^{1}$ In metacontrast masking, a prime is followed after a certain interval by a laterally adjoining stimulus. This leads to strong backward-masking effects, which are largest with priming SOAs of about $60 \mathrm{msec}$ (Bachmann, 1994; Breitmeyer, 1984; Breitmeyer \& Ogmen, 2000; Enns \& Di Lollo, 1997; Kahneman, 1968; Lefton, 1973; Neumann \& Müsseler, 1990b). The Fröhlich effect is the onset mislocalization of a quickly moving stimulus in the direction of its movement (Aschersleben \& Müsseler, 1999; Carbone, 2001; Müsseler \& Aschersleben, 1998). These phenomena may be explained as effects of the asynchronous updating of sensory codes and attentional allocation specified in the AUM. 
The AUM rests upon a distinction and an interaction between lower and higher processing levels within the cognitive system (recently, this interaction has been interpreted as a case of iterative or reentrant processing by $\mathrm{Di}$ Lollo, Enns, \& Rensink, 2000). Incoming signals are preattentively and continually registered on a spatial map (mainly, such features as size, orientation, contours, color, motion, etc.; Enns \& Rensink, 1991; Treisman, 1986; Wolfe, 1992). Changes of stimulation in this spatial map initiate attentional allocation toward the location of the change. Thus, an abrupt onset stimulus will entail feature processing, as well as a shift of attention toward the processed features (Rensink, O'Regan, \& Clark, 1997). Attentional allocation is a precondition for transferring a stimulus into an internal model, which in turn may give rise to conscious perception. As compared with ongoing feature coding, the attentional response is a slow process (Müller \& Findlay, 1988; Sperling \& Reeves, 1980; Tsal, 1983). This asynchrony causes phenomena such as those mentioned above. In metacontrast masking, a transient signal of the prime initiates a shift of attention. When this is completed, the prime's features have been substituted or overwritten by those of the mask, which is actually being encoded in the spatial map. Thus, the mask is visible, whereas there is no recognition of the prime (for related models, see Bachmann, 1984, 1994, 1999, and Enns \& Di Lollo, 1997; see also Di Lollo et al., 2000; Rensink et al., 1997). The mislocalization of the first position of a moving stimulus (Fröhlich effect) can also be explained by this asynchrony: Owing to the duration of the attentional shift, the first positions of the stimulus in the spatial map will not be attended, and a later position is transferred into the internal model.

The answer to the question of how visual awareness arises is a second crucial feature of the AUM. Attended stimuli or feature assemblies in the spatial map will be transferred into internal models, which in turn may give rise to conscious perception (Wolfe, 1992; Wolfe \& Bennett, 1997). According to the classical difference between judgment and response (see, e.g., Neumann \& Müsseler, 1990a), awareness of stimuli is a necessary precondition for a judgment. Thus, the primed stimulus is perceived as the earlier one, since it is consciously available earlier.

In Scharlau and Neumann (in press), this explanation was tested against an alternative account of sensory facilitation or sensory priming - that is, facilitation of the processing of the mask's features by previous processing of the prime (Bar \& Biederman, 1998; Haber \& Hershenson, 1965; Hershenson \& Haber, 1965; Wiggs \& Martin, 1998). The authors demonstrated that perceptual latency priming depends neither on figural overlap between the prime and the target nor on the degree to which the prime is masked by the target. In the light of these findings, a sensory explanation is unlikely; but they are in accordance with the AUM.

For priming SOAs of up to $100 \mathrm{msec}$, it has been demonstrated that the perceptual latency priming effect is smaller than the priming SOA and approximately half its size
(Aschersleben, 1999; Neumann et al., 1993; Scharlau \& Neumann, in press; Steglich \& Neumann, 2000). A simple explanation for this half-SOA rule would be onset averaging. In TOJ experiments with priming, a single event at one of the locations is compared with a double event at the other location - the onsets of two stimuli in close succession. If stimulus presentation frequency approaches thresholds for temporal resolution of visual events (King, 1962), signal averaging may be a strategy for inferring onsets.

Likewise, the P-center hypothesis can predict the halfSOA regularity (Scott, 1998) and would thus be an alternative account of perceptual latency priming. The concept of P-centers (perceptual centers) was originally developed in speech perception research (Morton, Marcus, \& Frankish, 1976) and described the finding that the perceived onset of a speech stimulus (e.g., a syllable) may largely differ from its actual onset. Later, it was transferred to simpler tonal stimuli (Schütte, 1978; Terhardt \& Schütte, 1976). Here, P-centers depend on duration and onset, as well as offset, parameters, - - for example, abruptness (Aschersleben \& Prinz, 1995; Scott, 1998; Vos, Mates, \& van Kruysbergen, 1995). Recently, P-centers were proposed as a general concept of the moment of occurrence, or functional onset, of a stimulus, independent of sensory modality, thus generalizing to perceptual timing processes and perception of intervals and order with discrete stimuli (Scott, 1998). Possible influences of functional onsets on temporal perception in TOJ tasks with visual targets have been demonstrated by Jaskowski (1991, 1993). In contrast to the AUM, attention does not play a role in the P-center account. The P-center hypothesis would predict that the perceived onset of a prime-target sequence lies somewhere between these two stimuli because of general mechanisms by which functional onsets are inferred.

The AUM and the P-center account make similar predictions about the influence of leading primes. A leading prime will influence the perceived onset of the target in the direction of the prime. This predating will increase with increases in priming SOA. According to the AUM, it arises because of attentional allocation by the prime, and the enlargement with longer priming SOAs is due to the increasing time for initiation, execution, and completion of the attentional shift. According to the alternative accounts, the effect arises because a functional onset is built in the event sequence of onsets and likely offsets of the two stimuli. Also, this effect will increase numerically with increases in the priming SOA or event duration. (If the SOA exceeds a maximum, an additional gain is implausible, and the priming effect should level off or be reduced. The AUM expects a leveling off as soon as the SOA is large enough to complete the attentional shift. According to the P-center account, building of functional onsets with large intervals between the events is implausible [see Scott, 1998], although there is no precise prediction about the maximum duration.) However, the predictions about trailing primes are clearly different. According to the AUM, the effect of the prime arises because it draws at- 
tention toward a previously unattended visual location. If the prime follows the target, it cannot act as an attentional signal. Thus, the AUM excludes an influence of trailing primes on the perceived onset or perceptual latency of the target. According to the P-center and onset-averaging accounts, functional onsets of closely timed events will be built independently of their temporal order. Thus, an influence of trailing primes (reversed- or backward-priming effect) is expected.

In contrast to the latter accounts, perceptual latency priming was explained as an attentional effect in Scharlau and Neumann (in press). Although, in this study, the explanation by the AUM was successfully tested against an alternative account by sensory facilitation, there was no attempt to exclude the onset-averaging or the P-center hypothesis. In the present paper, I will present evidence against the latter accounts.

\section{OVERVIEW}

The experiments reported below were designed to test the attentional explanation of perceptual latency priming by the AUM against the onset-averaging and the P-center accounts. Experiment 1 explores whether trailing primes influence TOJ in a way similar to that for leading primes. In a dual-task setting, both effects were found: perceptual latency priming by leading stimuli and a backward effect by trailing stimuli. The latter effect is predicted by the onset-averaging and the P-center hypotheses, both of which cover a mechanism for inferring onsets independently of the order of presentation. The AUM, however, restricts perceptual latency priming to conditions in which the prime precedes the target and, thus, may act as an attentional signal. According to this model, the effect of trailing primes is of nonattentional-for example, sensory or decisional-origin. The aim of Experiments 2 and 3 was to dissociate the effects. By this means, the explanation of the AUM was tested against the P-center account by simplifying the task (Experiment 2 ) and by masking the prime (Experiment 3). According to the latter explanations, the influence of trailing primes should arise independently of task difficulty or masking. However, both manipulations reduce occasions for a judgment or response bias, which might be an alternative explanation of the effect of trailing primes found in Experiment 1.

\section{EXPERIMENT 1}

In Experiment 1, the influences of leading and trailing primes on TOJ were compared. It was designed to test whether trailing primes exert a similar, if any, influence on TOJ as leading primes. Also, the temporal perception of the prime was investigated. If computation of functional onsets or P-centers is a general mechanism in TOJs, a systematic influence on the prime's perceived temporal position would be expected independently of whether the primes precede or follow the target. The AUM excludes an influence of trailing primes on the latency of perception, whereas alternative explanations, such as the P-center hypothesis, would expect primes to influence perceived onsets independently of their position within a short sequence of events.

Originally, Experiment 1 was motivated by another question. Scharlau and Neumann (in press) found that perceptual latency priming was independent of masking strength. Effects of the same size were found with well-masked and easily visible primes. This led us to investigate the onset of a prime that predated the perceived onset of a target following at its location. The AUM predicts that the prime speeds up conscious availability of the target by acting as an attentional signal. An influence on the prime's onset is not included (see Aschersleben, 1999, for similar considerations). However, participants quite often reported spontaneously seeing the prime after the target, even in experiments in which it was always the leading stimulus. ${ }^{2}$ Thus, Experiment 1 was originally designed to assess whether a prime's perceived onset is influenced by its predating the perceived onset of a following stimulus by acting as an attentional signal. To achieve this, two TOJs were combined. Participants had to compare the onsets of either two successive stimuli at the same location (prime and target) or two successive stimuli at different locations (target and target). Effects on the prime's onset should show up in the comparison of the prime and the target. The comparison of targets assesses perceptual latency priming. Combining these judgments in an experimental session opens the possibility of exploring both effects simultaneously.

\section{Method}

Participants. Fifteen voluntary participants from a panel took part in the experiment ( 9 female; mean age, 27.1 years). One participant did not show up for the second session, and his data from the first session were excluded from analysis. The participants received

18 or course credits. All reported normal or corrected-to-normal visual acuity.

General design. The experiment consisted of two sessions. Since it was designed to assess the perceived onset of a stimulus priming a target, we had to ensure that this perceptual latency priming indeed took place. Accordingly, the participants were not informed about the TOJ (prime-target or target-target; in the following I will refer to these tasks as prime TOJ and target TOJ) until after presentation of the stimuli. Strategies were controlled by varying judgment probability. In one of the sessions, the participants had to perform a target TOJ in $80 \%$ of the trials, whereas the prime TOJ was rare $(20 \%)$. In the other session, the latter was frequent $(80 \%)$, and the target TOJ was rare $(20 \%)$. In the first session, the prime was not task relevant and, thus, was not the central focus of attention. Nevertheless, it should speed up perception of the target at its location (perceptual latency priming). Thus, if the perceived onset of the prime was altered by the perceptual latency priming it initiated, the effect should show up in this session. In the second session, the participants were expected to attend primarily to the prime. By this means, discrimination performance of dating the prime in comparison with the primed target could be tested. In addition, this session addressed the question of whether an attended prime may still influence the perceived onset of a target at its location. Sessions were administered in varying order to the participants.

Apparatus. The stimuli were presented black $\left(14 \mathrm{~cd} / \mathrm{m}^{2}\right)$ on white background $\left(103 \mathrm{~cd} / \mathrm{m}^{2}\right)$ on a 17 -in. color monitor with a refresh rate of $132 \mathrm{~Hz}$. The participants sat in front of a computer monitor in a 
Targets of Experiment 1
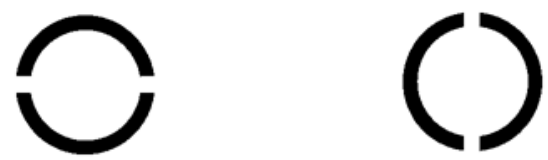

Prime of Experiment 1

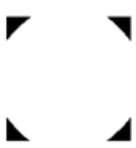

Targets of Experiment 2 and 3

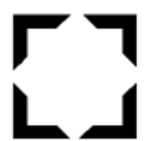

Prime of Experiment 2

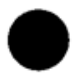

Primes of Experiment 3
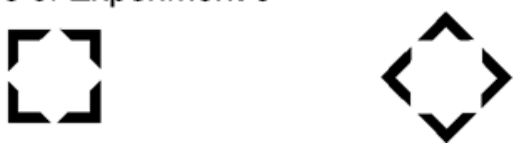

Figure 1. Stimuli employed in the experiments. In Experiment 3 , a target was always combined with a prime of identical shape.

dimly lit room, their head arrested by a chinrest and their line of gaze straight ahead, with viewing distance fixed at $60 \mathrm{~cm}$. They responded by pressing either the left or the right key of a mouse, using their dominant hand. The experiment was controlled by a computer that also served for data recording.

Stimuli. In each trial, three stimuli were presented, a prime and a target pair (see Figure 1). The target pair was aligned horizontally either above or below fixation. Fixation was marked by a small rectangle in the center of the screen. Construction of the targets and the prime was determined by the following considerations: The prime should be equally dissimilar to each of the targets, and masking should be minimized. Results from preliminary tests hinted at an additional problem: The double task was very difficult if the stimuli were of short duration, especially with respect to the prime, which was to some extent masked by the target. Thus, the primes and the targets were presented until the participants responded. In order to make the prime and the target at the same location easily discriminable, it was necessary to prevent them from forming a common Gestalt, especially one in which one of the stimuli seemed to be placed above or below the other one, which could be a cue impairing temporal order perception. Thus, we took care not to foster figural integration or binding between the target and the prime. These conditions were met by the stimuli. The targets were rings $\left(2.3^{\circ}\right.$ in diameter), with a gap in either the horizontal or the vertical direction. The primes consisted of four triangles arranged on an imaginary square (side length, $2.5^{\circ}$ ) surrounding the ring. Each stimulus was located at a distance of approximately $6^{\circ}$ above and below or left and right of fixation - that is, the to-be-compared target was separated by $12^{\circ}$, which should prevent apparent motion perception. The primes and targets were present on the screen until judgment. A fixation spot consisting of a small black rectangle was visible on the screen throughout the experiment.

Four hundred milliseconds after presentation of the stimuli, an auditory signal instructed the participants whether they had to perform a prime or a target TOJ. In each session, a sinewave signal of $220 \mathrm{~Hz}$ was assigned to the frequent TOJ, and a signal of $880 \mathrm{~Hz}$ was assigned to the rare TOJ. In order to make the auditory signal easy to discriminate, each signal was presented for 100 cycles, resulting in a long low-pitch and a short high-pitch sound.

Procedure. The participants were seated in front of a computer screen. In each trial, three stimuli, one prime and two targets, were presented in horizontal alignment, either above or below fixation in an unpredictable order. Assignment of the two target shapes to the two locations in each trial was also randomized. All the stimuli were present until the participants responded. The targets were presented with SOAs between -72 and $+72 \mathrm{msec}$ in steps of $24 \mathrm{msec}$. One of the targets was preceded or succeeded by a prime. The SOA between the prime and the target was $+72,+24,-24$, or $-72 \mathrm{msec}$, negative numbers denoting that the prime followed the target at the same location and positive numbers indicating a leading prime (for a sample trial with a leading prime, see Figure 2). The priming SOA was measured with respect to the primed stimulus, since the investigated attentional effect was location specific. Any temporal sequence of prime, primed target, and unprimed target was realized, including conditions in which the prime and the unprimed target or both targets were presented simultaneously, although at different locations. Each of the two shapes was primed equally often. Thus, there were 28 conditions ( 7 target SOAs $\times 4$ priming SOAs). Each condition was presented 40 times in each session in a random order. An additional factor was the TOJ to perform. In 32 out of 40 repetitions of each condition, the frequent TOJ was demanded, whereas the rare TOJ was performed in the remaining 8 repetitions.

In each session, the participants judged the temporal order either of the targets or of the prime and the target at the same location. One of the TOJs was frequent $(80 \%)$ and the other was rare $(20 \%)$ in each session. The participants were informed in advance about these probabilities. With respect to the target TOJ, half of the participants responded with the left mouse button when they saw the horizontally divided ring first and with the right button when the vertically disrupted ring was perceived first; for the other half, the assignment was reversed. When a prime TOJ was performed, for the first group the left button was assigned to prime first and the right one to target first. Again, this assignment was reversed for the other group. The instruction emphasized accuracy and did not require fast responding. Before data were recorded, the participants had the opportunity to practice until they were sure that they understood the instructions, could discriminate the auditory signals, and were familiar with the task. A session lasted approximately $80 \mathrm{~min}$. Every 100 trials, a break was initiated automatically.

\section{Results}

Frequent prime TOJ. To construct psychometric functions, the frequency of the prime first judgment was computed for each priming SOA, target SOA, and participant. Logit analysis (Finney, 1971) was used to estimate the point of subjective simultaneity (PSS) and the difference limen (DL, defined as the interquartile range) for each participant. If necessary, degrees of freedom were corrected by the Greenhouse-Geisser coefficient $\varepsilon$, and alpha was adjusted accordingly (Hays, 1988).

The PSS of the prime and the comparison target and the DL were computed for each target SOA and participant. 


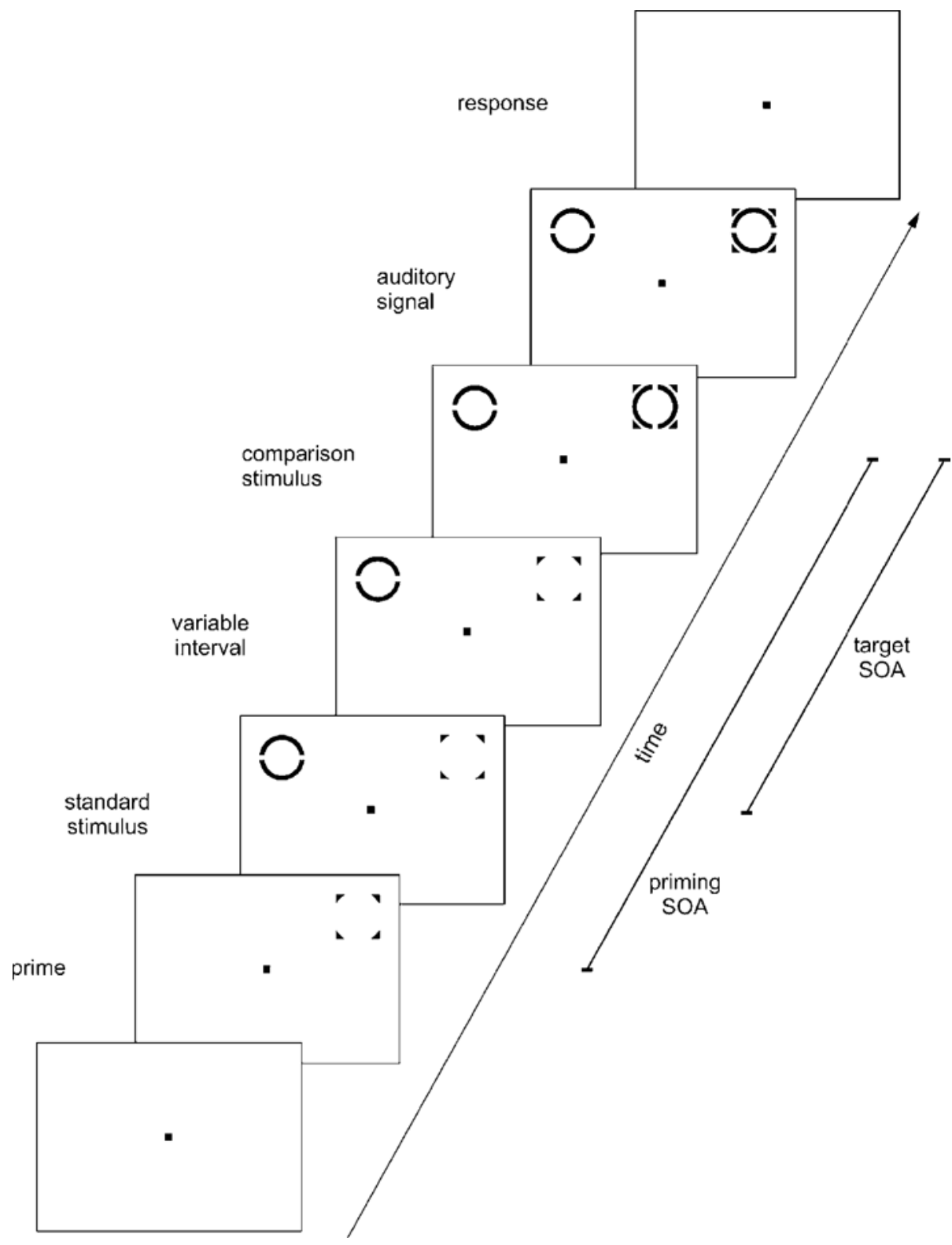

Figure 2. Succession of events in a sample trial of Experiment 1.

For 1 participant, computation of parameters was not possible for every target SOA, owing to poor performance. There was no influence of target SOA on perceived of temporal order: PSS did not depend on target SOA $(F<1)$. The influence of target SOA on discrimination performance (DL) was marginally significant $[\mathrm{F}(6,78)=3.65$, $p=.0542, \varepsilon=.2657]$. If there was any, there was a tendency for larger DLs with larger target SOAs. This influence of target SOA was restricted to the DL. However, PSS is the parameter of main interest in Experiment 1, and PSS was not influenced by target SOA. Thus, the data were collapsed across target SOAs for the subsequent analysis. As can be seen from Figure 3 (upper left), only a small proportion of the psychometric distribution could be assessed by our method. The participants' performance was quite poor.

The mean PSS was $+26 \mathrm{msec}$ (i.e., the prime had to be presented $26 \mathrm{msec}$ before the target in order to be perceived as simultaneous, or in other words, the temporal position of the prime seems to be postdated). This would conform to a systematic reversal of the temporal order reported by the participants. However, a $t$ test of PSS against zero revealed no significant deviation from zero $[t(13)=$ $1.4, p=.1848]$. An inspection of individual data showed that the large positive average PSS value was due to a single participant who denoted the prime the first event in $61 \%$ to $75 \%$ of the trials and whose psychometric function was very shallow $(\mathrm{DL}=265 \mathrm{msec})$. As reduced by this 

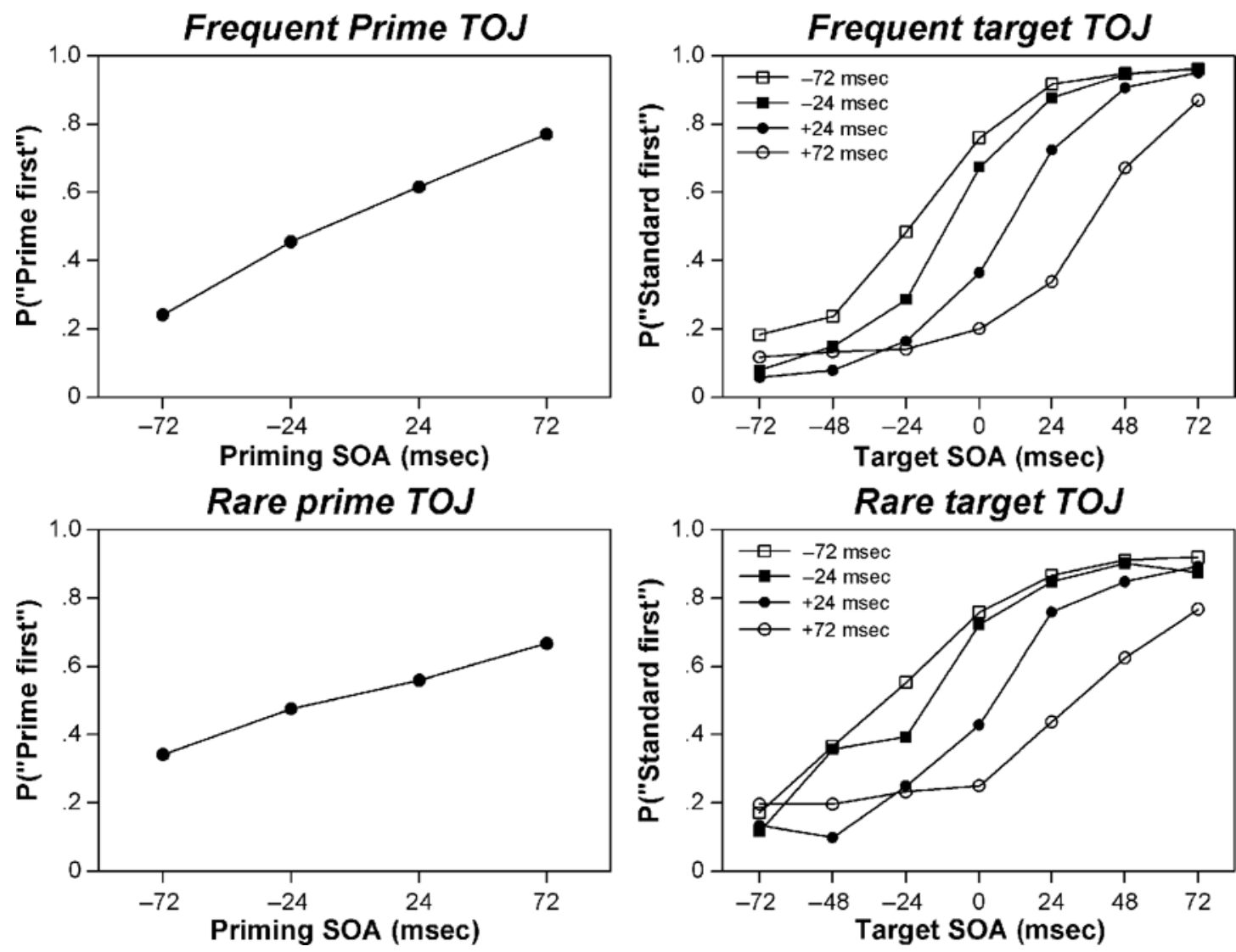

Figure 3. Results of Experiment 1. In the upper panels, the results from frequent conditions are shown; in the lower panels, the results from rare conditions are shown. The left panels depict the psychometric functions for the prime temporal order judgment (TOJ). In the right panels, psychometric functions for the target TOJ are shown.

participant, the mean PSS was $+8 \mathrm{msec}$ and did not differ from zero $[t(12)=1.31, p=.1852]$. Mean DL was $75 \mathrm{msec}$ with and $61 \mathrm{msec}$ without the participant mentioned above and, thus, about twice as large as discrimination performance measures for target TOJ (see below).

Rare prime TOJ. For 2 participants, computation of parameters was not possible, owing to poor performance. PSS was not influenced by target SOA $[F(6,66)=2.37$, $p=.0859, \varepsilon=.5136]$. There was a small tendency toward the PSS values' deviating from zero in the larger target SOAs. No influence was found on DL $[F(6,66)=1.09$, $p=.3653, \varepsilon=.4713]$. The data thus were collapsed across target SOA. The psychometric distribution is shown in Figure 3, lower left. With the prime TOJ being rare, the PSS was again close to zero (i.e., $-9 \mathrm{msec}$ ) and did not significantly differ from zero $[t(14)=-0.34, p=.7389]$. Performance was even poorer than in the first part reported above, since DL was up to $160 \mathrm{msec}$ in this part. PSS did not vary in correspondence with the frequency with which the judgment was demanded $[t(12)=0.53, p=.6053]$, although DL $\operatorname{did}[t(12)=2.64, p<.05]$.

Frequent target TOJ. The primed target was defined as the comparison stimulus, and the unprimed target was defined as the standard stimulus. Negative values denote target SOAs in which the comparison stimulus preceded the standard stimulus; negative values for priming SOAs again indicate that the prime was presented after the target stimulus. Figure 3 (upper right) shows the relative frequencies of the standardfirst response as a function of target SOA and for the different priming SOAs. The shape of the psychometric functions for all the priming conditions is roughly sigmoid. Inspection of the data of individual participants indicated that this was also the case at the individual level and that the individual distributions could be approximated by logistic functions. In this part of the experiment, the data from 1 participant had to be omitted, since she indicated standard first in 889 of 896 trials, probably owing to insufficient instruction. As can be seen in Figure 3 (upper right), psychometric functions are horizontally displaced, owing to priming condition. There was a significanteffect of priming SOA on PSS $[F(3,36)=$ $7.2, p<.05, \varepsilon=.3504$ ]. PSSs were $57 \mathrm{msec}$ (priming SOA of $+72 \mathrm{msec}), 13 \mathrm{msec}(+24 \mathrm{msec}),-5 \mathrm{msec}$ $(-24 \mathrm{msec})$, and $-16 \mathrm{msec}(-72 \mathrm{msec})$. Note that this is not the amount of perceptual latency priming, since no unprimed conditions were included and perceptual latency 
priming was quantified in comparison with unprimed trials. However, there was no influence of priming SOA on $\operatorname{DL}[F(3,36)=3.39, p=.0862, \varepsilon=.3607]$. Mean DL was $26 \mathrm{msec}$

Rare target TOJ. As Figure 3 (lower right) shows, an attended prime is able to influence a rare target TOJ. There is again a horizontal displacement of psychometric functions. With a priming SOA of $24 \mathrm{msec}$, the PSS amounted to $+5 \mathrm{msec}$, whereas a prolonging of this SOA to $72 \mathrm{msec}$ enlarged the PSS to $+26 \mathrm{msec}$. For the prime following the target, PSS amounted to $-20 \mathrm{msec}$ (priming SOA of $-24 \mathrm{msec}$ ) and $-31 \mathrm{msec}(-72 \mathrm{msec})$. An analysis of variance (ANOVA) of individual PSSs confirmed the priming effect on the target $\operatorname{TOJ}[F(3,36)=12.9, p<$ $.001, \varepsilon=.5917]$. Again, the amount of perceptual latency priming could not be estimated. In addition, there was no effect of priming SOA on discrimination performance. An ANOVA of the DL revealed no significant influence $[F(3,39)=0.76, p=.4494, \varepsilon=.5125]$. Mean DL was 33 msec.

Discrimination performance in the target TOJ did not differ according to session - that is, the frequency with which the judgment was demanded. A two-way ANOVA of the DL revealed no effect of frequency and priming SOA and no interaction [frequency, $F(1,12)=0.30, p=$ .5917 ; priming SOA, $F(3,36)=0.89, p=.455, \varepsilon=$ .5196 ; interaction, $F(3,36)=0.52, p=.6721, \varepsilon=.4963]$. In addition, PSS depended on priming SOA $[F(3,36)=$ 15.23, $p<.001, \varepsilon=.4636]$, although not on judgment frequency $[F(1,12)=0.29, p=.6011]$. An interaction of frequency and priming SOA was not found $[F(3,36)=$ $0.24, p=.7148, \varepsilon=.4811]$.

\section{Discussion}

As the results of the prime TOJ demonstrate, the perceived onset of a prime is not mislocalized in time, independently of whether the prime is attended to (frequent prime TOJ) or not (rare prime TOJ), and under conditions in which this prime influences the perceived onset of a second stimulus at its location. This may be taken as evidence against onset-averaging and P-center accounts, since there is no reason why averaged onsets or P-centers should show up in the target, but not in the prime, TOJs. Experiment 1 confirms the results of Aschersleben (1999), who demonstrated correct dating of a prime in synchronization tasks. Additional evidence can be found in studies on the kappa effect. The kappa effect may be observed if participants judge temporal intervals between stimuli at various spatial distances. Small distances between the stimuli shorten the perceived temporal interval between them, whereas larger distances increase the interval. However, it is known that dating the first stimulus within a sequence is not influenced by this sequence, whereas for later stimuli, there are influences of spatial distribution (Aschersleben \& Müsseler, 2000).

Perceptual latency priming in the target TOJ was found in both tasks, independently of whether the participants attended mainly to the prime/comparison or to the target pair. PSSs in the target TOJ were independent of temporal discrimination of prime and comparison stimulus. The lack of differences between the two tasks or judgment frequencies demonstrates that the latency effect of the prime is quite robust and arises under easier, as well as more difficult, conditions.

On the other hand, leading and trailing primes had a roughly symmetrical effect on temporal order perception. Leading the target, they shifted psychometric functions as expected. If they followed the target, there was a shift in the opposite direction. Perceptual latency priming could not be quantified from the data in Experiment 1, since there was no condition without a prime. It would have been desirable to include such a condition. However, I decided to do without unprimed trials, since perceptual latency of the prime and the target should be assessed under strictly identical sensory conditions and trials without a prime do not allow a comparison of a prime and a target. Nevertheless, psychometric functions and, especially, PSS values indicate that there may have been a reversed priming effect - that is, a prime presented after a target shifted its onset backward in time. This reversed or backward priming is not predicted by the AUM. If the effect of the prime on perceptual latency arises because it draws attention toward a previously unattended visual location, a trailing prime should not have a symmetrical effect, since in this case, the target itself acts as an attentional signal. Thus, the AUM excludes backward priming and is not in accordance with the results shown above. However, there is the possibility that a certain proportion of the trials was influenced by a judgment error: The participants erroneously compared the standard stimulus and the prime (instead of the standard and comparison stimuli).

However, backward priming would be predicted by the onset-averaging hypothesis, as well as by the P-center hypothesis, which could also, as was mentioned in the introduction, account for the amount of perceptual latency priming. In this respect, the data from the target TOJ in Experiment 1 render P-centers a serious alternative account for perceptual latency priming.

Thus, it was desirable to investigate whether (1) a backward-priming effect in TOJ indeed exists and (2) it is as large as perceptual latency priming itself. Data from Experiment 1 hint to both possibilities. Since primes were clearly visible in Experiment 1, backward priming may have been due to a judgment bias by the prime. If the latter account is correct, then (1) backward priming should vanish, or at least be minimized, if there is less attentional load by the double task and the prime is to be ignored, as in standard TOJ experiments, and (2) backward priming should vanish if the prime is invisible. These predictions were addressed in Experiments 2 and 3.

One additional result should be mentioned that is not directly connected with the issues discussed here. The perceptual latency priming effect reported in earlier studies in which primes were of short duration was also found with 
primes and targets without offset. Thus, perceptual latency priming seems, as the AUM predicts, not to depend on transient offset but exclusively on onset signals (for an opposite account, see Jaskowski, 1991).

\section{EXPERIMENT 2}

Experiment 2 simplified the experimental task in comparison with Experiment 1. The participants always performed a target TOJ. By this means, the backward-priming effect was inspected in detail. According to the AUM, I expected the backward-priming effect to vanish, or at least to be diminished, in this experiment, since the simpler task left less occasion for judgment bias. On the other hand, perceptual latency priming should show up as usual.

The time course of the effects of primes has rarely been investigated, owing to the fact that perfect or good backward masking is possible only for a small range of SOAs. Vorberg, Mattler, Heinecke, Schmidt, and Schwarzbach (in press) and Schmidt (2000) found robust effects up to approximately $100 \mathrm{msec}$, whereas Aschersleben (1999) noted a reduced effect on PSS with SOAs of $80 \mathrm{msec}$. In order (1) to collect first evidence on the time course of perceptual latency priming and (2) to compare a possible reversed- or backward-priming effect with the wellknown positive effect over a broad range of SOAs, Experiment 2 included priming SOAs as large as $144 \mathrm{msec}$. As was mentioned in the introduction, the AUM expects the priming effect to increase with increases in priming SOA and to remain constant roughly after intervals that are sufficient for the execution of an attentional shift.

\section{Method}

Participants. Thirteen voluntary participants from a panel took part in the experiment ( 7 female; mean age, 26.5 years). They received 9 or course credits. In addition, there were rewards of 7.50 and 5 for the 2 participants with the highest discrimination performance. All reported normal or corrected-to-normal visual acuity.

General design. The experiment consisted of two sessions with the same task (target TOJ). Two sessions were necessary because of the large number of trials.

Apparatus. The apparatus did not differ from that in Experiment 1 .

Stimuli. In Experiment 1, several participants complained that the target stimuli were difficult to discriminate, possibly contributing to the somewhat poorer performance. Thus, the stimuli from previous studies were used again. The target pair consisted of a square and a diamond with star-shaped inner contours (see Figure 1, third row), originally developed by Klotz (1996) in the context of the metacontrast masking paradigm. The prime was a circle depicted in the center of the target with, as precisely as possible, the same intensity as the target (number of pixels; Figure 1, fourth row).

Procedure. The participants were seated in front of a computer in a dimly lit room. A fixation assistance consisting of a small black rectangle was visible on the screen throughout the experiment. In each trial, three stimuli, one prime and two targets, were presented in horizontal alignment, either above or below fixation in unpredictable order. Assignment of the two shapes to the two locations in each trial was randomized. All the stimuli were present until the participants responded. Targets were presented with SOAs of -200 , $-80,-40,+40,+80$, and $+200 \mathrm{msec}$. One of the targets was preceded by a prime. The SOA between the prime and the target was $-144,-96,-48,0,+48,+96$, or $+144 \mathrm{msec}$, negative SOAs de- noting a trailing prime and positive SOAs a leading prime. As in Experiment 1 , any temporal sequence of prime, comparison stimulus, and standard stimulus was possible. However, there was only one sequence with two stimuli appearing simultaneously (prime-target SOA of $0 \mathrm{msec}$ ). The positions of the primed targets were balanced, and each of the two shapes was primed equally often. Thus, there were 42 conditions ( 6 target SOAs $\times 7$ priming SOAs). Each condition was presented 16 times in each session in a random order, resulting in a total of 32 repetitions per condition.

In both sessions, the participants judged the temporal order of the targets. Half of the participants responded with the left mouse button when they saw the square first and with the right button when the diamond was perceived first; for the other half, the assignment was reversed. The participants were instructed to ignore the prime. The instruction emphasized accuracy and did not require fast responding. Before data were recorded, the participants had the opportunity to practice until they were sure that they understood the instructions and were familiar with the task. A session lasted approximately $45 \mathrm{~min}$. Every 50 trials, a break was initiated automatically.

\section{Results}

Data were treated as described above. The upper part of Figure 4 depicts the backward-priming conditions together with the comparison condition (zero-priming SOA), the lower part the perceptual latency priming conditions, again with the comparison trials. It can be seen that there was only a slight backward-priming effect, whereas perceptual latency priming was substantially larger. An ANOVA of individual PSSs revealed a highly significant effect of priming $[F(6,72)=32.22, p<.0001, \varepsilon=.3748]$, whereas there were no effects on the DL $[F(6,72)=2.06, p=$ $.1625, \varepsilon=.2397]$.

To find out which priming conditions the PSS shift depended on, PSS differences between all primed conditions and the zero condition were computed and tested against zero. In the conditions with trailing primes, PSS differences were $-2,-11$, and $-15 \mathrm{msec}$ for priming SOAs of $-48,-96$, and $-144 \mathrm{msec}$. With leading primes, they were $+34,+55$, and $+53 \mathrm{msec}$ for the respective positive priming SOAs. Only the priming effect in the condition with smallest negative priming SOA $(-48 \mathrm{msec})$ did not differ significantly from zero $[F(12)=-0.28, p=.7833]$. Both of the other backward-priming effects did differ from zero $[\mathrm{SOA}-144, t(12)=-3.08, p<.01 ; \mathrm{SOA}-96, t(12)=$ $-3.5, p<.001]$, and for positive SOAs, tests were highly significant $[\mathrm{SOA}+48, t(12)=7.02, p<.0001 ; \mathrm{SOA}$ $+96, t(12)=7.75, p<.0001 ; \mathrm{SOA}+144, t(12)=4.62$, $p<.001]$.

An additional statistical analysis was performed in order to test whether the magnitude of the effects of leading and trailing primes differed. For each priming SOA (independently of whether negative or positive), the absolute magnitude of priming effects of leading and trailing primes was computed for each participant and submitted to a onetailed $t$ test. Effects of leading primes were stronger for all SOAs $[$ SOA $48, t(12)=2.53, p<.05 ;$ SOA 96, $t(12)=$ $5.02, p<.0001 ;$ SOA 144, $t(12)=3.08, p<.01]$.

\section{Discussion}

The results from Experiment 2 may be summarized as follows. (1) There certainly is an influence of a trailing 

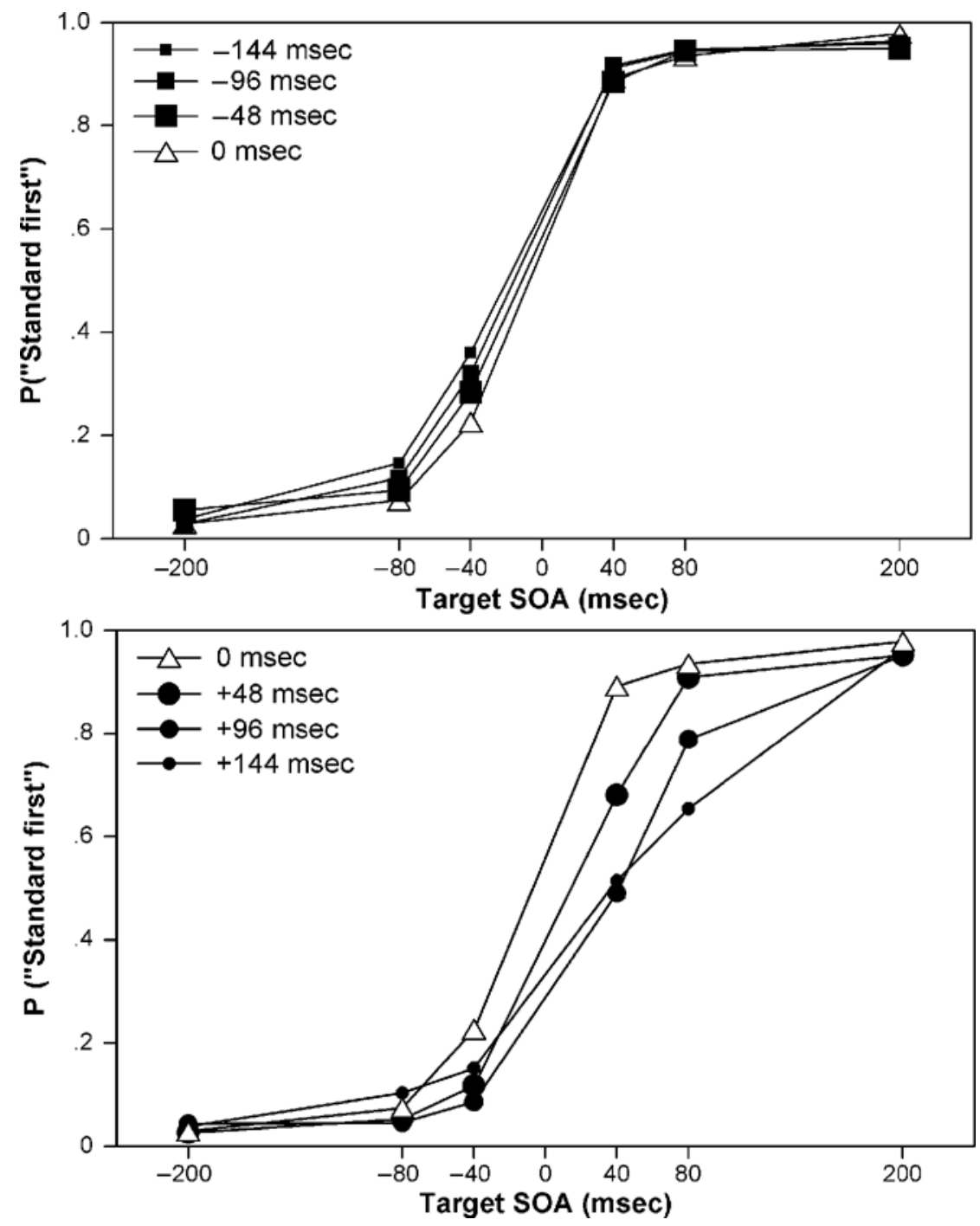

Figure 4. Psychometric functions of Experiment 2. The upper panel depicts conditions with trailing, and the lower panel depicts those with leading primes, both together with comparison trials (zero-priming SOA).

prime on the TOJ concerning the target that precedes it. (2) This effect is significantly smaller than the effect of a leading prime (see Figure 5). (3) It changes less in dependency on the priming SOA than perceptual latency priming does. The two effects were successfully dissociated in Experiment 2.

Experiment 2 gives additional evidence on the time course of priming effects in temporal perception. As Figure 4 (lower part) shows, psychometric functions of priming SOAs up to $+96 \mathrm{msec}$ are horizontally displaced, as compared with the unprimed condition. This may be taken as evidence that priming effects may be found with intervals up to this size, in contrast to Aschersleben's (1999) assumption that the effect may break down with SOAs as small as $80 \mathrm{msec}$. On the other hand, there is a marked change in the psychometric function with an SOA of +144 : The slope of this function is much flatter. This phenomenon has been repeatedly found in our laboratory and complicates the exploration of the time course of perceptual latency priming. With priming SOAs larger than $100 \mathrm{msec}$, the prime and the target tend to be perceived as clearly separate events. This will lead participants to adopt different strategies for excluding the prime from the TOJ. Typically, with large priming SOAs, individual psychometric functions are very different and result in highly variable PSSs.

On the other hand, Experiment 2 indicates that the priming effect does not drop off to zero with the largest priming SOA. This is in accordance with the AUM. According to this model, the priming effect should increase with 


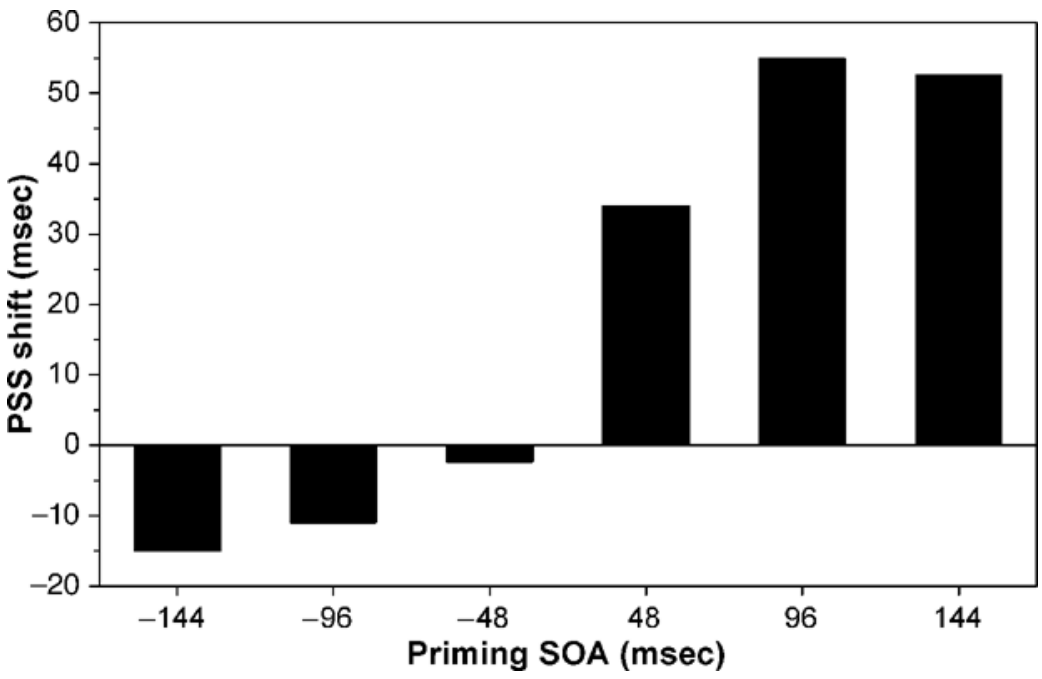

Figure 5. Point of subjective simultaneity (PSS) shifts in Experiment 2. The depicted priming effect is the difference between the PSS in the respective primed condition and the PSS in the zero-priming SOA condition.

priming SOA over a certain range and then reach an asymptote, which should approximately correspond to the duration of the attentional shift. If the priming SOA is longer than the time needed for attentional allocation, there should be neither an additional gain nor a reduced effect, except for additional strategy effects or such phenomena as inhibition of return or the inability to hold attention at a fixed location without stimulation. Both temporal characteristics are in accordance with cuing effects, which typically peak around SOAs of about $150 \mathrm{msec}$ and reach an asymptote a little later, a time course that is not very different from that reported here in the TOJ paradigm (see the General Discussion section). The psychometric functions of trailing primes do not differ. There is a very small horizontal displacement, indicating a minor PSS shift, but no effect on the slope, indicating a different time course of the effects of trailing primes.

Taken together, these results, size and time course, suggest that the two effects reflect different mechanisms. An explanation for the small reversed effect and the large perceptual latency priming could be that Experiment 2 could not sufficiently exclude the possibility of judgment errors or biases. This may have been due to the fact that the primes were clearly visible.

In order to reduce the visibility of the trailing prime and, thus, prevent a judgment bias, it would be convenient to mask it. Paracontrast is a means of forward masking of a stimulus by a preceding, laterally adjacent mask. Formally, paracontrast and metacontrast seem to be symmetrical. However, their functional properties are quite different (Breitmeyer \& Ganz, 1976; Fraisse, 1971). For example, paracontrast is never as efficient as metacontrast masking (Alpern, 1953; Breitmeyer, 1984; Breitmeyer \& Ganz, 1976). The metacontrast masking function, typically U-shaped with minimal visibility at SOAs of about
$60 \mathrm{msec}$ and still impaired visibility with simultaneous presentation of masked and masking stimuli, may be smoothly continued with SOAs smaller than zero (paracontrast; see Enns \& Di Lollo, 1997, for recent examples). Although, depending on task variables (Breitmeyer, 1984), the paracontrast masking function may be U-shaped as well, with a minimum between 20 and $120 \mathrm{msec}$ (Breitmeyer \& Ganz, 1976), it is much shallower, indicating less efficient masking. Thus, temporally symmetrical metacontrast and paracontrast primes that, according to both the onset averaging and the P-center hypotheses, will lead to the same absolute amount of priming will not be similarly masked. Fortunately, the amount of masking is not critical for perceptual latency priming (Aschersleben, 1999; Scharlau \& Neumann, in press).

\section{EXPERIMENT 3}

Experiment 3 was designed to reduce the visibility of the prime and, thereby, the occasion for a judgment bias. For that, primes masked by metacontrast and by paracontrast were employed. The AUM predicts that trailing primes exert no attentional influence on the TOJ. From the literature on the P-center hypothesis, no specific thesis concerning the influence of masked stimuli on P-centers can be drawn. However, any influence should be independent of order of appearance of the stimuli-that is, symmetrical effects of leading and trailing masked primes are to be expected.

\section{Method}

Participants. Thirteen voluntary participants from a panel took part in the experiment ( 6 female; mean age, 24.8 years). The participants received 3 or course credits. All reported normal or correctedto-normal visual acuity. 
General design. The experiment consisted of one session.

Apparatus. The apparatus did not differ from that in Experiment 1 .

Stimuli. The targets were the same stimuli as those used in Experiment 2. As primes, smaller replicas of these targets, fitting into the inner contours of the targets, were used. These primes allow good metacontrast, as well as paracontrast, masking (Klotz \& Neumann, 1999; Scharlau \& Neumann, in press). A target was always preceded or followed by a prime of the same shape. All the stimuli were presented dark $\left(14 \mathrm{~cd} / \mathrm{m}^{2}\right)$ on light background $\left(103 \mathrm{~cd} / \mathrm{m}^{2}\right)$.

Procedure. The procedure did not differ from that in Experiment 2, except for the following points. The targets were presented for $48 \mathrm{msec}$, with an SOA of $-120,-80,-40,+40,+80$, or $+120 \mathrm{msec}$. One of the targets was preceded by a prime presented for $8 \mathrm{msec}$. The SOA between the prime and the target was either -64 or $+64 \mathrm{msec}$ (negative values signaling paracontrast masking), or no prime was presented. Thus, there were 18 conditions (6 target SOAs $\times 3$ priming conditions). Each condition was presented 32 times in each session in a random order. Task and mapping were the same as those in Experiment 2. A session had a duration of approximately $30 \mathrm{~min}$. Every 50 trials, a break was initiated automatically.

\section{Results}

As Figure 6 indicates, Experiment 3 was successful in eliminating the backward-priming effect: Psychometric functions for paracontrast masked primes and unprimed trials are virtually indistinguishable, whereas the metacontrast distribution clearly is horizontally displaced. The mean PSS in the unprimed conditions was $2 \mathrm{msec}$, in the paracontrast conditions it was $-1 \mathrm{msec}$, and in the metacontrast trials it amounted to $40 \mathrm{msec}$. An ANOVA of the PSS yielded a highly significant effect of priming $[F(2,24)=$ $105.32, p<.0001, \varepsilon=.9602$ ]. Influences of priming on discrimination performance could not be found. The DL was $36 \mathrm{msec}$ in unprimed, $33 \mathrm{msec}$ in paracontrast, and $35 \mathrm{msec}$ in metacontrast conditions $[F(2,24)=1.72, p=$ $.2082, \varepsilon=.7683]$.

The amount of perceptual latency priming in each condition was computed by subtracting the PSS. Mean perceptual latency priming with paracontrast-masked primes was $3 \mathrm{msec}$ and did not significantly differ from zero $[F(12)=-1.04, p=.3207]$, whereas perceptual latency priming in metacontrast-masked trials with $38 \mathrm{msec}$ was of the usual size $[F(12)=11.29, p<.0001]$.

\section{Discussion}

Experiment 3 was successful in its aim to dissociate the effects of leading and trailing primes by masking them. With paracontrast-masked primes, there was no backwardpriming effect. However, Experiment 3 revealed the large perceptual latency priming effect with metacontrastmasked primes. Whereas the visible primes in Experiment 2 at least occasionally led the participants to base their judgments on the primes instead of the targets, in Experiment 3 there was no such possibility, owing to masking, and the small backward-priming effect disappeared. This is evidence against the onset-averaging and the P-center hypotheses, both of which assume that perceived onsets do not depend on the order in which events are presented.

\section{GENERAL DISCUSSION}

The experiments reported above draw a coherent picture. Priming a target by a leading prime reduces the perceptual latency of this target. Presenting the same prime after the target may influence the TOJ, but this effect is very likely of different origin. It is large under double-task conditions in which the response-relevant stimuli are unknown in advance, much smaller with a single simple TOJ task, and ineffective if the primes are masked. These properties render an additional explanation for the backwardpriming effect likely: Since discrimination performance for two stimuli at the same location is poor, participants may erroneously compare the prime with the standard stimulus, instead of judging the comparison and the standard

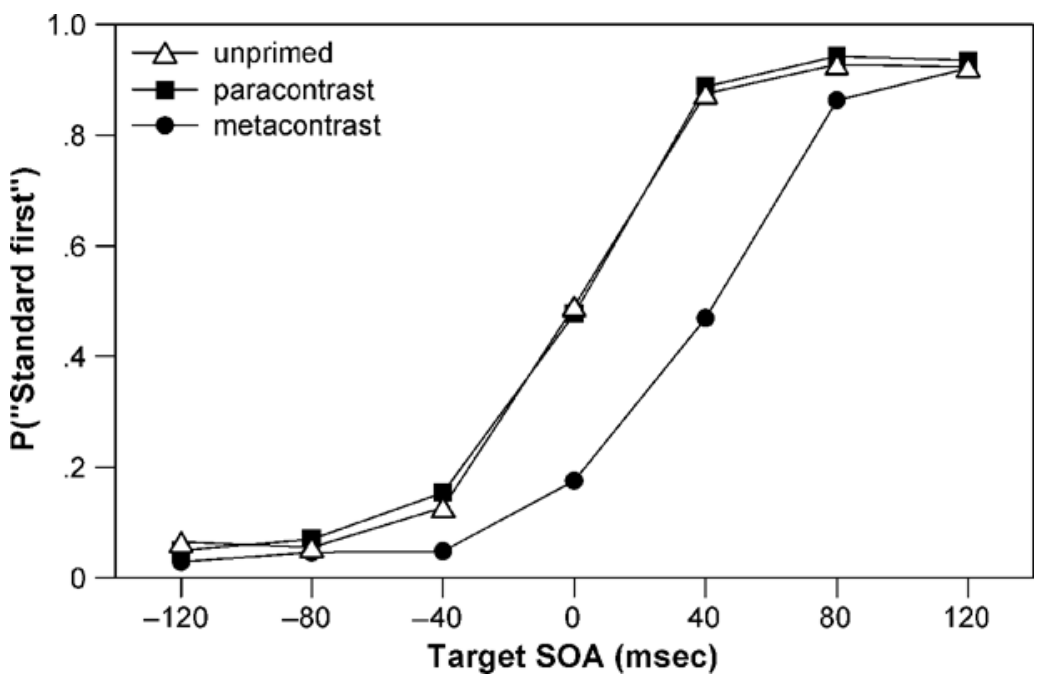

Figure 6. Psychometric functions of Experiment 3. The distribution for unprimed trials is marked by triangles, leading primes by circles, and trailing primes by squares. 
stimuli. This error is frequent if the trailing prime is an object of attention and visible (Experiment 1) and still likely if the prime always is to be ignored but is visible (Experiment 2). However, no effect of a trailing prime can be found if it is masked (Experiment 3). In contrast to this, perceptual latency priming can be found with double tasks, single tasks, and poorly, as well as strongly, masked leading primes. Since no trace of onset averaging and Pcenters was found in the paracontrast conditions of Experiment 3, perceptual latency priming cannot be due to averaging the onsets or building a P-center of the stimuli at the same location. This further validates the explanation for perceptual latency priming given by the AUM (Neumann \& Müsseler, 1990b; Scharlau \& Neumann, in press): The perceptual latency of a target may be shortened by a peripheral display change, either masked or unmasked, that initiates a transient attentional response toward its location.

With the present data, it is not possible to identify the origin of a leading prime's influence on a TOJ clearly. The main finding is that effects of leading and trailing primes can be dissociated. For the influence of trailing primes, there are several possible mechanisms. Response bias could account for the effect of trailing primes in two respects. Primes could, in principle, initiate a motor response directly. This account has been used to explain the finding that primes influence $\mathrm{RT}$ and error rate in speeded RT tasks, depending on their response congruency with the target (e.g., Klotz \& Neumann, 1999; Neumann, 1990). However, in TOJ tasks, no differential effects of congruent and incongruent primes have been found (Scharlau $\&$ Neumann, in press, Experiment 2), so this explanation can be ruled out. Also, the studies reported here and elsewhere (Neumann et al., 1993; Scharlau \& Neumann, in press; Steglich \& Neumann, 2000) used orthogonal variation of attentional manipulation (left or right) and response demands (reporting on the basis of form, and not location, of the target), which has been claimed to be insensitive to response biases (Shore, Spence, \& Klein, 2001). Apart from that, response bias may be relevant at decisional stages in processing, in the form of a criterion of acceptability effect (second order bias; Shore et al., 2001; see Frey, 1990, for examples in psychophysical experiments, and Jaskowski, 1991, for TOJ data). With ambiguous stimulus input, such as, for example, small target SOAs, participants may be biased to assign the criterion (firstness) to a target favored by any salient feature-for example, being primed. This explanation cannot be ruled out on the basis of the present experiments. It is possible that trailing primes induce a decisional or response bias against ascribing firstness to the primed stimulus. However, in Experiment 1, it was found that performance of the participants in the target TOJ condition did not depend on its frequency. No response bias could be induced directly by making the task of judging the targets more difficult by mainly attending to the prime-comparison pair. Nevertheless, the magnitude of the influence of trailing primes depended on their task relevance and visibility. Both characteristics might indicate a judgment bias origin. Apart from response bias, onset averaging or P-center hypotheses would be able to explain the small backwardpriming effect by the concept of functional onsets. This account proposes that, apart from actual onsets, perceived onsets depend on additional features of the stimulus-for example, its duration or onset and offset characteristics. Which of these mechanisms is responsible for the effect has to be clarified by further investigation. However, it was possible to dissociate the effects of leading and trailing primes on TOJ and, thus, support the AUM's attentional explanation.

An additional aim of the present study was to gain first insights into the time course of perceptual latency priming. Some of the results reported above are not consistent with the half-SOA rule mentioned in the introduction. In Experiment 2, the PSS shift amounted to approximately half the SOA with a priming SOA of $96 \mathrm{msec}$, but it was enlarged to nearly three quarters of the SOA with a smaller SOA and was reduced to a third with a longer SOA. Thus, perceptual latency priming may be larger than half the priming SOA with small SOAs, and it may reach its maximum size with SOAs of little more than $100 \mathrm{msec}$. This pattern would correspond well to the AUM. If the prime's effect is mediated via attentional allocation-that is, the initiation or even completion of an attentional shift toward the prime's location-perceptual latency priming should increase with increases in the priming SOA up to a certain value corresponding to the time needed for the attentional shift, and it should remain constant afterward.

For the metacontrast masking paradigm, there are only a few studies about the time course of priming effects (Aschersleben, 1999; Schlaghecken \& Eimer, 1997, 2000; Schmidt, 2000; Vorberg et al., in press). Partly, this is due to the fact that metacontrast masking itself depends on time, and with priming SOAs shortly above $100 \mathrm{msec}$, there is no substantial masking. In addition, most of the studies of the priming paradigm have used the RT paradigm in which the effects of congruent primes (i.e., primes specifying the same response as the target) are compared with incongruent primes (demanding the alternative response) or neutral primes that do not specify any response (Ansorge, Klotz, \& Neumann, 1998; Klotz \& Neumann, 1999; Schlaghecken \& Eimer, 1997, 2000; Vorberg et al., in press). This response priming is not involved in priming effects measured by TOJ. As was reported in Scharlau and Neumann (in press, Experiment 2; see also Heumann \& Scharlau, 2001), the effects of congruent and incongruent primes on TOJ are indistinguishable. This further confirms the interpretation that in TOJ experiments, the prime acts as an attentional signal or cue.

The time course of cuing effects is well established, starting with Eriksen and Collins (1969) and Eriksen and Rohrbaugh (1970), who demonstrated that letter discrimination will be enhanced by cues up to a cuing SOA of $200 \mathrm{msec}$, after which performance decreases. Facilitation by a cue reaches its peak about $100-150 \mathrm{msec}$ after cue onset (see, e.g., Müller \& Findlay, 1987, 1988; Müller \& 
Rabbitt, 1989; Nakayama \& Mackeben, 1989; Posner \& Cohen, 1984; Suzuki \& Cavanagh, 1997). After 200$300 \mathrm{msec}$, this facilitation declines somewhat, although not completely, and may later be replaced by inhibition (inhibition of return; see Gibson \& Egeth, 1994; Posner \& Cohen, 1984; Reuter-Lorenz, Jha, \& Rosenquist, 1996). The temporal course of a fast rise and slow decay of facilitation elicited by a peripheral cue was interpreted as arising because of two components of attention. One is a fast-rising and fast-decaying transient component, which is automatically elicited by a cue and is not under voluntary control. The other, sustained component rises slower and does not decay with time (e.g., Müller \& Findlay, 1987, 1988; Nakayama \& Mackeben, 1989; Yantis, 1996). These dynamics were found in discrimination tasks (Müller \& Findlay, 1987, 1988; Müller \& Rabbitt, 1989), visual search and Vernier tasks (Nakayama $\&$ Mackeben, 1989), and in the attentional repulsion effect (Suzuki \& Cavanagh, 1997). The time course of perceptual priming effects found in the present study corresponds well to these findings, although facilitation found in the TOJ paradigm may be slightly smaller. Experiment 2 hints at the possibility that the effect is already declining with priming SOAs of $144 \mathrm{msec}$, temporal conditions under which cuing effects have their peak.

The TOJ paradigm is well suited for scrutinizing the time course of attentional effects initiated by peripheral stimulation changes. The most prominent feature of the data is that the psychometric distributions of primed trials are horizontally displaced, as compared with unprimed trials (Experiment 3; Scharlau \& Neumann, in press). A transformation of their shape (indicated, e.g., by the parameter DL) typically is not found except with long priming SOAs, where the DL is substantially enlarged (see Experiment 2). Thus, with this exception, temporal perception of unprimed and primed trials seems exclusively affected by perceptual latency priming. This finding is interesting in that it indicates that perceptual latency priming does not depend on target SOA - that is, the temporal sequence of the primed target and an unprimed target. Several authors found that the early, transient attentional component elicited by a peripheral cue is highly resistant to interruption by the appearance of a distractor (Müller \& Findlay, 1987, 1988; Nakayama \& Mackeben, 1989; Suzuki \& Cavanagh, 1997). However, the findings with the TOJ paradigm do not correspond to this interpretation. Even with target SOAs smaller than $100 \mathrm{msec}$, the time that is typically required for the transient attentional component, a second target can be attended, and the prime exerts an influence independently of whether it is the first or the second display event.

\section{REFERENCES}

Alpern, M. (1953). Metacontrast. Journal of the Optical Society of America, 43, 648-657.

Ansorge, U., Klotz, W., \& Neumann, O. (1998). Manual and verbal responses to completely masked (unreportable) stimuli: Exploring some conditions for the metacontrast dissociation. Perception, 27, $1177-1189$
Aschersleben, G. (1999). Aufgabenabhängige Datierung von Ereignissen [Task-dependent timing of events]. Aachen: Shaker Verlag.

Aschersleben, G., \& Müsseler, J. (1999). Dissociations in the timing of stationary and moving stimuli. Journal of Experimental Psychology: Human Perception \& Performance, 25, 1-12.

Aschersleben, G., \& Müsseler, J. (2000). Datierung visueller Reize bei einer raum-zeitlichen Wahrnehmungstäuschung (Kappa-Effekt) [Timing of visual stimuli in a spatio-temporal perceptual illusion (the Kappa effect)]. In G. Baratoff \& H. Neumann (Eds.), Dynamische Perzeption (pp. 163-166). Sankt Augustin: Infix.

Aschersleben G., \& Prinz, W. (1995). Synchronizing actions with events: The role of sensory information. Perception \& Psychophysics, 57, 305-317.

BaChMAnN, T. (1984). The process of perceptual retouch: Nonspecific afferent activation dynamics in explaining visual masking. Perception \& Psychophysics, 35, 69-84.

Bachmann, T. (1989). Microgenesis as traced by the transient pairedforms paradigm. Acta Psychologica, 70, 3-17.

Bachmann, T. (1994). Psychophysiology of visual masking: The fine structure of conscious experience. Commack, NY: Nova.

Bachmann, T. (1999). Twelve spatiotemporal phenomena and one explanation. In G. Aschersleben, T. Bachmann, \& J. Müsseler (Eds.), Cognitive contributions to the perception of spatial and temporal events: Advances in psychology (pp. 173-206). Amsterdam: Elsevier, North-Holland.

Bar, M., \& Biederman, I. (1998). Subliminal visual priming. Psychological Science, 9, 464-469.

Breitmeyer, B. G. (1984). Visual masking: An integrative approach. Oxford: Oxford University Press.

Breitmeyer, B. G., \& GANZ, L. (1976). Implications of sustained and transient channels for theories of visual pattern masking, saccadic suppression, and information processing. Psychological Review, 83, $1-36$.

Breitmeyer, B. G., \& OGmen, H. (2000). Recent models and findings in visual backward masking: A comparison, review, and update. Perception \& Psychophysics, 62, 1572-1595.

Carbone, E. (2001). Die Rolle von Aufmerksamkeitsprozessen bei der Fehlwahrnehmung dynamischer Reize [The role of attention in misperception of dynamic stimuli]. Unpublished doctoral dissertation, University of Bielefeld.

Di Lollo, V., EnNs, J. T., \& Rensink, R. A. (2000). Competition for consciousness among visual events: The psychophysics of reentrant visual processes. Journal of Experimental Psychology: General, 129, 481-507.

ENnS, J. T., \& Di Lollo, V. (1997). Object substitution: A new form of masking in unattended visual locations. Psychological Science, 8 , 135-139.

Enns, J. T., \& Rensink, R. A. (1991). Preattentive recovery of threedimensional orientation from line drawings. Psychological Review, 98, 335-351.

Eriksen, C. W., \& Collins, J. F. (1969). Temporal course of selective attention. Journal of Experimental Psychology, 80, 254-261.

ERIKSEN, C. W., \& Rohrbaugh, J. W. (1970). Some factors determining efficiency of selective attention. American Journal of Psychology, 83, 330-342.

Finney, D. J. (1971). Probit analysis (3rd ed.). Cambridge: Cambridge University Press.

FraISSE, P. (1971). Parameters of visual simultaneity and of metacontrast and paracontrast of successively presented letters. Perception \& Psychophysics, 10, 185-188.

Frey, R. D. (1990). Selective attention, event perception, and the criterion of acceptability principle: Evidence supporting and rejecting the doctrine of prior entry. Human Movement Science, 9, 481-530.

Gibson, B. S., \& EGETH, H. (1994). Inhibition and disinhibition of return: Evidence from temporal order judgments. Perception \& Psychophysics, 56, 669-680.

Haber, R. N., \& Hershenson, M. (1965). Effects of repeated brief exposures on the growth of a percept. Journal of Experimental Psychology, 69, 40-46.

HaYs, W. L. (1988). Statistics (4th ed.). Orlando, FL: Holt, Rinehart \& Winston. 
Hershenson, M., \& Haber, R. N. (1965). The role of meaning in the perception of briefly exposed words. Canadian Journal of Psychology, 19, 42-46.

Heumann, M., \& Scharlau, I. (2001, August). Judgment vs. response. Poster presented at the summer workshop, "Sensorimotor Integration," Delmenhorst, Germany.

JASKOWSKI, P. (1991). Perceived onset simultaneity of stimuli with unequal durations. Perception, 20, 715-726.

JASKOWSKI, P. (1993). Temporal-order judgment and reaction time to stimuli of different rise times. Perception, 22, 963-970.

KaHneman, D. (1968). Method, findings, and theory in studies of visual masking. Psychological Bulletin, 70, 404-425.

KING, H. E. (1962). Two-flash and flicker fusion thresholds for normal and schizophrenic subjects. Perceptual \& Motor Skills, 14, 517-518.

KLOTz, W. (1996). Handlungssteuerung ohne bewußte Wahrnehmung: Eine experimentelle Untersuchung zur motorischen Verarbeitung visuell maskierter Reize [Action control without conscious perception: An experimental study of motor processing of visually masked stimuli]. Unpublished doctoral dissertation, University of Bielefeld.

Klotz, W., \& Neumann, O. (1999). Motor activation without conscious discrimination in metacontrast masking. Journal of Experimental Psychology: Human Perception \& Performance, 25, 976-992.

Lefton, L. A. (1973). Metacontrast: A review. Psychonomic Monograph Supplements, 4 (Whole No. 62), 245-255.

Morton, J., Marcus, S., \& Frankish, C. (1976). Perceptual centers (Pcenters). Psychological Review, 83, 405-408.

Müller, H. J., \& Findlay, J. M. (1987). Sensitivity and criterion effects in the spatial cuing of visual attention. Perception \& Psychophysics, 42, 383-399.

Müller, H. J., \& Findlay, J. M. (1988). The effect of visual attention on peripheral discrimination thresholds in single and multiple element displays. Acta Psychologica, 69, 129-155.

MülleR, H. J., \& RABBiTt, P. M. A. (1989). Reflexive and voluntary orienting of visual attention: Time course of activation and resistance to interruption. Journal of Experimental Psychology: Human Perception \& Performance, 15, 315-330.

Müsseler, J., \& Aschersleben, G. (1998). Localizing the first position of a moving stimulus: The Fröhlich effect and an attention-shifting explanation. Perception \& Psychophysics, 60, 683-695.

NaKayama, K., \& Mackeben, M. (1989). Sustained and transient components of focal visual attention. Vision Research, 29, 1631-1647.

Neumann, O. (1978). Visuelle Aufmerksamkeit und der Mechanismus des Metakontrasts [Visual attention and the mechanism of metacontrast] (Rep. No. 6/1978). Bochum, Germany: Ruhr-University Bochum, Department of Psychology, Cognitive Psychology Unit.

Neumann, O. (1979). Kann ein nicht bewußt repräsentierter Reiz eine Willkürbewegung auslösen? Zur Interpretation des Fehrer-RaabEffektes [Is a nonconscious stimulus able to initiate a voluntary action? On the Fehrer-Raab effect]. In P. Wolff \& M. Tücke (Eds.), Report on the 3rd Psychology Meeting in Osnabrück, Germany, October 1979, Psychological reports from Department 3, Osnabrück University.

Neumann, O. (1982). Experimente zum Fehrer-Raab-Effekt und das "Wetterwart"- Modell der visuellen Maskierung [Experiments on the Fehrer-Raab effect and the "weather station" model of visual masking] (Rep. No. 24/1982). Bochum, Germany: Ruhr-University Bochum, Department of Psychology, Cognitive Psychology Unit.

NeumanN, O. (1990). Visual attention and action. In O. Neumann \& W. Prinz (Eds.), Relationships between perception and action: Current approaches (pp. 227-267). Berlin: Springer-Verlag.

Neumann, O., Esselmann, U., \& Klotz, W. (1993). Differential effects of visual-spatial attention on response latency and temporal order judgment. Psychological Research, 56, 26-34.

NeumanN, O., \& Müsseler, J. (1990a). "Judgment" vs. "response": A general problem and some experimental illustrations. In H.-G. Geißler (Ed.), Psychophysical explorations of mental structures (pp. 445455). Göttingen: Hogrefe.

Neumann, O., \& Müsseler, J. (1990b). Visuelles Fokussieren: Das Wetterwart-Modell und einige seiner Anwendungen [Visual focusing: The weather station model and some applications]. In C. Meinecke \&
L. Kehrer (Eds.), Bielefelder Beiträge zur Kognitionspsychologie (pp. 77-108). Göttingen: Hogrefe.

Posner, M. I. (1980). Orienting of attention. Quarterly Journal of Experimental Psychology, 32, 3-25.

Posner, M. I., \& CoHEN, Y. (1984). Components of visual orienting. In H. Bouma \& D. G. Bouwhuis (Eds.), Attention and performance $X$ : Control of language processes (pp. 531-556). Hillsdale, NJ: Erlbaum.

Posner, M. I., Snyder, C. R. R., \& Davidson, B. J. (1980). Attention and the detection of signals. Journal of Experimental Psychology: General, 109, 160-174.

Rensink, R. A., O'Regan, J. K., \& Clark, J. J. (1997). To see or not to see: The need for attention to perceive changes in scenes. Psychological Science, 8, 368-373.

Reuter-Lorenz, P. A., Jha, A. P., \& Rosenduist, J. N. (1996). What is inhibited in inhibition of return? Journal of Experimental Psychology: Human Perception \& Performance, 22, 367-378.

Scharlau, I., \& Neumann, O. (in press). Perceptual latency priming by metacontrast-masked stimuli: Evidence for an attentional interpretation. Psychological Research.

Schlaghecken,F., \& Eimer, M. (1997). The influence of subliminally presented primes on response preparation. Sprache \& Kognition, 16, 166-175.

Schlaghecken, F., \& Eimer, M. (2000). A central-peripheral asymmetry in masked priming. Perception \& Psychophysics, 62, 13671382.

Schmidt, T. (2000). Visual perception without awareness: Priming responses by color. In T. Metzinger (Ed.), Neural correlates of consciousness: Empirical and conceptual questions (pp. 157-189).Cambridge, MA: MIT Press.

SchÜTTE, H. (1978). Ein Funktionsschema für die Wahrnehmung eines gleichmäßigen Rhythmus in Schallimpulsfolgen [A functional scheme for perception of regular rhythms in sound sequences]. Biological $\mathrm{Cy}$ bernetics, 29, 49-55.

Scott, S. K. (1998). The point of P-centers. Psychological Research, 61, 4-11.

Shore, D. I., Spence, C., \& Klein, R. M. (2001). Visual prior entry. Psychological Science, 12, 205-212.

Sperling, G., \& Reeves, A. (1980), Measuring the reaction time of a shift of visual attention. In R. S. Nickerson (Ed.), Attention and performance VIII (pp. 347-360). Hillsdale, NJ: Erlbaum.

Steglich, C., \& Neumann, O. (2000). Temporal, but not spatial, context modulates a masked prime's effect on temporal order judgment, but not on response latency. Psychological Research/Psychologische Forschung, 63, 36-47.

SuzUKI, S., \& CAVANAGH, P. (1997). Focused attention distorts visual space. An attentional repulsion effect. Journal of Experimental Psychology: Human Perception \& Performance, 23, 443-463.

Terhardt, E., \& Schütte, H. (1976). Akustische RhythmusWahrnehmung: Subjektive Gleichmäßigkeit [Acoustical rhythm perception: Subjective regularity]. Acustica, 35, 122-126.

Treisman, A. (1986). Properties, parts and objects. In K. R. Boff, L. Kaufmann, \& J. P. Thomas (Eds.), Handbook of perception and human performance (pp. 1-70). New York: Wiley.

TsaL, Y. (1983). Movements of attention across the visual field. Journal of Experimental Psychology: Human Perception \& Performance, 9 , 523-530.

Vorberg, D., Mattler, U., Heinecke, A., Schmidt, T., \& Schwarz$\mathrm{BACH}, \mathrm{J}$. (in press). Invariant time-course of priming with and without awareness. In C. Kaernbach, E. Schröger, \& H. J. Müller (Eds.), Psychophysics beyond sensation: Laws and invariants of human cognition. Mahwah, NJ: Erlbaum.

Vos, P. G., Mates, J., \& VAN Kruysbergen, N. W. (1995). The perceptual center of a stimulus as the cue for synchronisation to a metronome: Evidence from asynchronies. Quarterly Journal of Experimental Psychology, 48A, 1024-1040.

Wiggs, C. L., \& Martin, A. (1998). Properties and mechanisms of perceptual priming. Current Opinion in Neurobiology, 8, 227-233.

Wolfe, J. M. (1992). The parallel guidance of visual attention. Current Directions in Psychological Science, 1, 124-128. 
Wolfe, J. M., \& Bennett, S. C. (1997). Preattentive object files: Shapeless bundles of basic features. Vision Research, 37, 25-43.

YANTIS, S. (1996). Attentional capture in vision. In A. F. Kramer, M. G. H. Coles, \& G. D. Logan (Eds.), Converging operations in the study of visual selective attention (pp. 45-98). Washington, DC: American Psychological Association.

\section{NOTES}

1. This model has formerly been referred to as weather station model (Wetterwart-Modell), the metaphor illustrating some of the proposed processes that interfere between changes in peripheral stimulation and perception (attentional signals, monitoring changes in spatially organized maps/instruments, reading off contents of maps/instruments, etc.).
For the sake of theoretical clarity, this name is now replaced by one illustrating the main feature of explanations given by this model: asynchrony of sensory coding processes and attentional allocation.

2. As Breitmeyer and Ogmen (2000) noted, reversed perception of order in the masking paradigm may be predicted by the perceptual retouch model of Talis Bachmann (1984, 1994; Breitmeyer \& Ogmen, 2000). In this model, metacontrast masking is explained by the asynchrony of specific and nonspecific coding processes. According to Breitmeyer and Ogmen, this asynchrony may lead to a reversed perception of order.

(Manuscript received October 2, 2001; revision accepted for publication April 3, 2002.) 